\title{
LO NEOPÚBLICO: UN NUEVO ESPACIO EN INTERNET
}

\author{
José Julio Fernández Rodríguez ${ }^{1}$
}

SUMARIO: I. - Introducción. II. - Lo público frente a lo privado. III. - Lo Neopúblico, consecuencia de la Red. IV.- La dinámica de lo Neopúblico.

RESUMEN: Trátase en este artículo sobre el fenómeno de Internet y los cambios cualitativos y cuantitativos provocados por este, que los enfrenta y andliza el autor desde la óptica jurídica para conseguir proponer una regulación satisfactoria de la nueva realidad. Partiendo desde la descripción del problema, sitúa luego los espacios de lo público y de lo privado, de frente a una nuevo espacio, el de lo Neopúblico, donde se relativizan dichos espacios reconocidos como una consecuencia del desarrollo de la Red. Finalmente aborda la dinámica de este nuevo espacio, donde a la oposición entre medios de comunicación de masas y medios de comunicación individual parece romperse construyendo una nueva sociedad que transforma las relaciones humanas.

Palabras clave: Internet - Red - Público - Privado - Neopúblico Medios de Comunicación.

\section{INTRODUCCIÓN}

Internet ejemplifica el cambio que nuestras sociedades han experimentado en los últimos años. Esta Red de redes que conecta computadoras a nivel mundial es el recipiente que acoge un elevado número de reformulaciones de las categorías tradicionales que nos habían acompañado desde hace siglos. Estamos ante una mutación de categorías y pautas culturales a las que tiene que enfrentarse el ser humano con la digitalización de lo que le rodea y con su inmersión en la denominada Sociedad de la Información. No se trata de determinismo técnico sino de alteración de las pautas de referencia que permiten a la persona ubicarse en su contexto. Surgen, de este modo, cambios cualitativos y cuantitativos para nuestra propia existencia, que deben ser enfrentados y analizados desde la óptica jurídica para conseguir una regulación satisfactoria de la nueva realidad. El Derecho se ve afectado de manera particularmente intensa

Profesor Titular de Derecho Constitucional, Universidad de Santiago de Compostela (España). 
por la incidencia de Internet, una incidencia que está exigiendo replantear muchas de las instituciones jurídicas existentes y que reclama aproximaciones teóricas que arrojen luz a las oscuridades conceptuales que se derivan de la Red.

Internet se anuda a las ideas de interactividad, conectividad e instantaneidad. La interactividad alude a la capacidad de respuesta que permite al usuario del sistema adoptar posiciones activas y de participación. Surge, de este modo, una realidad multidireccional basada en el hipertexto. La hipertextualidad posibilita saltar de un sitio a otro y generar la sensación de navegación por la Red al romper las secuencias y la linealidad del relato. Parafraseando a Descartes se tiene afirmado que I link, therefore $I$ exist. Estar conectado te permite estar en el mundo, entrar en cualquier parte de él a través del hipervínculo que genera el hipertexto. Ello se refuerza por la facilidad de acceso a la Red. Dadas las reducidas dimensiones del planeta desde la perspectiva de la velocidad de la luz, los movimientos por la Red tienen un elemento de instantaneidad, aunque no absoluto por las rémoras de gestión.

Internet también se conecta a las ideas de mundialización y globalización. En efecto, el Estado se ve superado por un fenómeno que escapa, en gran parte, a su control. Internet es una telaraña de redes que carece de centro efectivo y que se expande saltando fronteras. Ni siquiera la interconexión entre los usuarios sigue rutas fijas. La Red tiene capacidad para renrutar datos si alguna de sus uniones no está accesible. Si el mensaje no llega a su destino es devuelto al punto de origen. Toda esta situación explica que el desarrollo de la Red corriera paralelo a un marcado sentimiento libertario, de raíces ácratas, que en gran parte sigue presente en la comunidad internáutica y que aflora cuando se intentan articular medidas intervencionistas.

En este momento tan solo queremos reflexionar sobre uno de los aspectos de la abigarrada problemática jurídica que genera la Red: el nacimiento de un nuevo espacio en la misma, denominado por nosotros, ya en otro lugar, Neopúblico ${ }^{2}$. Este espacio tiene particular incidencia en temas jurídicos de tanta envergadura como el ejercicio de los derechos fundamentales y el funcionamiento del sistema democrático, tal y como se hará evidente al lector en lo que sigue.

Vid. nuestro libro Lo público y lo privado en Internet. Intimidad y libertad de expresión en la Red, Instituto de Investigaciones Jurídicas, Universidad Nacional Autónoma de México, México D. F., 2004. Otros autores también se han acercado a esta cuestión, como ECHEVERRfA, que habla de un "tercer entorno" diferente a los entornos naturales y urbanos, sobre todo por la posibilidad de relacionarse e interactuar a distancia. El tercer entorno es "distal y reticular, mientras que los entornos naturales y urbanos (...) están basados en la proximidad y en la recintualidad (ECheverría EZPONDA, Javier: "Democracia y sociedad de la información", Isegoria, $\mathrm{N}^{\circ} 22,2000$, pp. 39 y ss.). 


\section{LO PÚBLICO FRENTE A LO PRIVADO}

En Internet la distinción entre lo público y lo privado se relativiza hasta tal punto que puede considerarse que se difumina. Ante ello surge un nuevo espacio, que hemos denominado Neopúblico, en el que se ejercen los derechos fundamentales, sometidos a nuevos peligros en la Red, pero también a inéditos mecanismos de protección. Parece conveniente, por lo tanto, hacer un breve recorrido por el tópico que viene constituido por las categorías de lo público y de lo privado, teniendo presente que solo se trata de hacer alguna reflexión sobre el mismo que nos sirva de mero enfoque situacional y no de evadirnos de nuestro hilo argumental.

En la Ciencia Jurídica hace mucho tiempo que se sedimentó la distinción entre el Derecho Público y el Derecho Privado, que, a pesar de que en más de una ocasión ha funcionado como un topos recurrente sin fundamento real, sí puede afirmarse que se amolda con corrección a la naturaleza del mundo del Derecho. La Filosofía jurídica ha entrado en multitud de ocasiones en la cuestión, al igual que la Teoría General del Derecho.

Es también lugar común, en este orden de cosas, citar a ULPIANO para mostrar el origen de esta distinción jurídica. Sus palabras, recogidas en el Digesto, sirven de base para mayores profundizaciones. Digesto 1.1.1: "publicum ius est quod ad statum rei romanae spectat, privatum quod ad singulorum utilitatem pertinet". Las funciones públicas se entendían publica iura por oposición a los privata hominis et familae iura. El ius publicum se consideraba ius cogens, es decir, Derecho imperativo, en la medida en que se funda en el imperativo de la lex publica y no puede ser alterado por los convenios de los particulares.

Siguiendo a PUY MUÑOZ, podemos detectar diversos conceptos de Derecho Privado que parten de la opinión de UlPIANO y que se basan en la idea de que el Derecho Privado es una especie del ordenamiento jurídico. En este sentido, se dice que Derecho Privado es el que trata de las relaciones entre los particulares; que es el conjunto de normas cuya actuación coactiva se ha de perseguir por la vía procesal civil; que es el que regula relaciones entre iguales; que es el que no distingue valorativamente los intereses enfrentados, sean de los individuos o de la colectividad; que es la normativa que pone en el mismo plano los intereses relativos a una materia, dejando a los interesados la prosecución de los mismos; que es la normativa cuya aplicación está condicionada a la voluntad de las partes; que es la parte del ordenamiento jurídico que no afecta directamente al poder político y está constituido por relaciones mediatas a través de las cosas, que, en uno y otro caso, adquieren la condición de relaciones jurídicas, al ser reguladas y protegidas; que es el conjunto de reglas que rigen las relaciones entre particulares y entre la Administración y los particulares que no exceden la órbita del Derecho común; o 
que es el referente a las cuestiones que pueden repercutir en el ámbito famíliar, primero, e individual, después ${ }^{3}$.

Este mismo autor también recoge los sentidos que se le dan al Derecho Público: conjunto de normas que rigen las relaciones entre el Estado, representado por sus órganos, y los súbditos jurídicos; el Derecho para el ámbito de los casos en que los particulares aparecen enfrentados al Estado; conjunto de normas jurídicas obligatorias; el caracterizado por el dominio del Estado sobre los individuos, expresado en el mandato y la coacción; normación jurídica que tiende a promover los intereses colectivos o a dar especial consideración al interés público; normación de la conducta humana que incluye una distinción valorativa, respecto a los intereses que entran efectivamente en cuestión, otorgando un valor superior a los intereses de la colectividad sobre los intereses de los individuos; normación jurídica que impone a los órganos públicos, respecto de cierta materia, el deber de velar de oficio por la salvaguardia de los intereses colectivos frente a los intereses individuales afectados; el que afecta a la autoridad del Estado; complejos normativos en los que la condición de la obligación establecida en las normas es una voluntad excraña al obligado; y un Derecho de subordinación que perfecciona las garantías jurídicas de la libertad individual, pero recortándola cada vez más en el orden externo.

A pesar de lo dicho, hay que reconocer que tanto el Derecho Privado como el Derecho Público van más allá de los predios de la normatividad para recaer en dimensiones subjectivas. Esta articulación tópica no debe hacer olvidar el acercamiento que se produce en determinado tipo de cuestiones entre el Derecho Público y el Derecho Privado. Un ejemplo prototípico para corroborar lo dicho es la protección de los consumidores, en donde se dan cita técnicas de ambos. Sea como fuere, esta distinción se arraigó en el pensamiento liberal y llenó de contenido parte de la construcción del Derecho del Estado Constitucional. Incluso, en el terreno de los derechos públicos subjetivos se dio cita esta aproximación tópica hablándose de los derechos de lo público (libertad de expresión) y de los derechos de lo privado (intimidad), ante cuyo conflicto era tarea imprescindible efectuar la oportuna ponderación de intereses en juego para inclinar la balanza en uno u otro sentido. No obstante, está claro que los derechos públicos subjetivos, máxime los que se consideren derechos fundamentales, forman parte del Derecho Público. Tales categorizaciones respondían a acervos culturales diferentes, que pueden esquematizarse en la opinión de DADER, que enfrenta "las tradiciones privatistas franco-continentales" a las "público-publicistas norteamericanas"4.

Puy Muñoz, Francisco: Tópica Jurídica. Paredes, Santiago de Compostela, 1984, pp. 328-329.

4 Dader, José Luis: Periodismo de procisión: la vía socioinformática de descubrit noticias, 1997, Sintesis, Madrid, p. 95. 
Desde estas posiciones jurídicas se puede saltar fácilmente al predio sociológico y distinguir un espacio público y un espacio privado. "El espacio público -sostiene Wolton- es algo específico de la historia moderna vinculado a la emergencia del individuo, a la libertad de conciencia y de palabra, y reclama numerosas condiciones culturales". "Para debatir libre y contradictoriamente -prosigue- se precisa, no solo lenguas comunes, sino también intereses comunes, territorios simbólicos comunes, expresiones públicas, es decir, el reconocimiento y el uso de un principio de publicidad"5. El espacio político, que algunos ven diferente al anterior, para nosotros es, a los efectos del presente trabajo, una parcela del espacio público. De aquí se salta a la simplificación del juego de intereses, articulada en torno a la idea de que lo público se refiere a lo que interesa al pueblo, a todos los miembros del grupo de que se trate, mientras que lo privado es lo relativo al interés exclusivo de la persona individualmente considerada. Generalizaciones al margen, es cierto que la lógica del interés presenta dinámicas diferentes en un espacio que en otro. Espacios distintos pero, sin duda, vinculados, y de manera inevitable porque el individuo aislado se socializa en el espacio público mediante la interacción social. No obstante, esta insoslayable vinculación no elimina la distinción entre ambas categorías.

Lo público y su espacio están jalonados de actores diversos que exacerban la carga simbólica del mismo. Lo público presupone la existencia, al mismo tiempo, del indíviduo, de su espacio y de su devenir vital autónomo. Ambos espacios tienen su traducción en determinadas ubicaciones físicas, ejemplificadas en la calle y en el propio domicilio. Ubicaciones físicas que reciben proyecciones diferentes y que levantan expectativas muy distintas. Ubicaciones, en suma, que sirven de referencia mutua para marcar delimitaciones y fronteras. Lo público implica la proyección de la libertad ciudadana y una dimensión exterior de la persona. Es el espacio de la discusión. Lo privado guarda celosamente a la intimidad. Es el espacio de la reflexión. Lo privado se opone a lo común y se acerca a la noción de secreto.

Lo público y lo privado también presentan una virtualidad que interesa a la politología. La democracia necesita imperiosamente un marco para desarrollarse: un espacio público para el intercambio de opiniones, el ejercicio del control del poder y la manifestación y construcción de la opinión pública. Pero, al mismo tiempo, requiere que la dimensión privada de los individuos permanezca protegida para que estos vean garantizada su libertad y participen en la vida pública y política sin desconfianzas.

5 Wolton, Dominique: Internet ‘y después, Gedisa, Barcelona, 2000, p. 183. 
Indica FREUND que los presupuestos de lo político son la relación del mandato y de la obediencia, la relación de lo privado y de lo público (que ordena la política interior) y la relación del amigo y del enemigo (que rige la política exterior) ${ }^{6}$. La idea política de lo público es producto de la Revolución liberal, que le otorga sentido sobre la base de la distinción entre sociedad civil y Estado. Así las cosas, apunta Ruiz Miguel, el liberalismo "protagonizará un proceso en el que la dominación convergerá con la razón gracias a la publicidad". De esta forma, "el poder como tal es puesto a debate por una publicidad políticamente activa"7. Lo público se erige como supuesto constitucional ${ }^{8}$.

\section{Lo NeOPÚblico, CONSECUENCIA DE LA RED}

Internet relativiza, desde diversos ángulos, esta distinción entre lo público y lo privado. En este sentido BASTERra también detecta "lo desdibujadas que están las fronteras entre lo público y lo privado" en la Red $^{9}$, opinión compartida por FERNÁNDEZ ESTEBAN ${ }^{10}$ y por DE AREILZA y DÍAZ DE RÁBAGO ${ }^{11}$. Estos últimos indican que "antes de la aparición de Internet, lo público y lo privado estaba claramente separado por barreras físicas y económicas". Ahora las cosas han cambiado. Se trata de una difuminación (permítasenos la palabra) de la diferencia entre lo público y lo privado, que se une y bebe del desvanecimiento que también se produce entre lo individual y lo colectivo, entre lo real y lo virtual. De igual modo, la Declaración Institucional del Observatorio Voto Electrónico (http://votobit.unileon.es:8000) de 1 de marzo de 2003 entiende que las modernas tecnologías de decisión modifican el contrato social entre lo público y lo privado. Ello forma parte de una cuestión de mayor calado, que podemos formular siguiendo a Wolton, como es la problemática innata a las tres grandes cuestiones de la modernidad: la comunicación, la cantidad y la relación entre esfera pública y privada en una sociedad abierta ${ }^{12}$. Así es, las implicaciones del desvanecimiento de la

FReUND, Jürgen: L'essence du politique, Sirey, $3^{a}$ ed., París, 1981, p. 94.

RUiz Miguel, Carlos; Servicios de inteligencia y seguridad en el Estado Constitucional, Tecnos, Madrid, 2002, p. 22.

Vid. De CABO De LA VEGA, A.: Lo público como supuesto constitucional, Instituto de Investigaciones Jurídicas, Universidad Nacional Autónoma de México, México D. F.

BASterRA, Marcela I.: "Libertad de prensa versus derecho a la intimidad", en V.v. A.A., Poder político y libertad de expresión, Abeledo-Perrot, Buenos Aires, 2001, p. 122.

FERnÁNDeZ Esteban, María Luisa: Nuevas tecnologías, Internet y derechos fundamentales, McGraw-Hill, Madrid, 1998, p. 142.

I MAYOR, Pablo y DE AReilza, José M.: Internet, una profecía, Ariel, Barcelona, 2002, p. 154 .

WOLTON, Dominique: (n. 5), p. 72. 
distinción van mucho más lejos de las consecuencias de la Red situándose en un abanico conceptual de amplias dimensiones. Es en esta óptica donde se sitúan las palabras de DADER: "lo público y lo privado no se entienden como campos estancos ni contradictorios sino como fluidos y complementarios" 13 . Este resquebrajamiento de los cimientos del tópico público-privado parece que juega en contra, sobre todo, de lo privado, pues, como también afirma en sentido concluyente el citado autor, "la defensa de la privacidad y la intimidad de todos los individuos implica la posibilidad de que el ojo público penetre en ocasiones en la privacidad e intimidad de algunos"14. Pese a todas estas implicaciones que se vislumbran, queremos centrar nuestras reflexiones en Internet porque su incidencia y sus consecuencias en el terreno de los derechos fundamentales son suficientemente ilustrativas como para aprehender este proceso de desvanecimiento conceptual. El desarrollo de las redes digitales tiene efectos que van mucho más allá de consideraciones técnicas dado que alteran las pautas de comportamiento personal e institucional, esgrimiendo nuevos interrogantes a las democracias occidentales.

Podría entenderse que este desvanecimiento de la distinción entre lo público y lo privado acaba en la desaparición del segundo concepto por mor de la expansión del primero. Ello se justificaría en una cuestión conectada con una suerte de ontología de la Red o de telos de la misma. Nos referimos a la concepción de Internet como un espacio de información pública, libre y accesible a quien entre en sus dominios. Esta, se ha esgrimido, es la cultura universal de Internet. Frente a ello estimamos que, si bien en un principio dicha descripción podía reflejar correctamente la esencia de la Red, en la actualidad han cambiado muchas cosas y el poder público y los usuarios han reaccionado frente a su pasividad anterior. De ahí que consideremos que el resultado del aludido desvanecimiento es la aparición de una nueva situación de ubicación del ser humano en su entorno, en donde ejerce sus derechos fundamentales. Para aludir a semejante nueva situación podrían manejarse, de inicio, tres términos: lo semipúblico, lo pseudopúblico y lo Neopúblico. El prefijo "semi" significa "medio" o "casi", "pseudo" significa "falso" y "neo" "reciente" o "nuevo". Siendo así la cuestión gramatical nos inclinamos por la tercera opción, lo Neopúblico, para referirnos al resultado del desvanecimiento entre lo público y lo privado. Sería una nueva manera de reflejarse lo público sin masas sino en conjunto de usuarios conectados digitalmente en una recreación de "realismo" virtual, o sea, de ficción que se percibe real. Esta situación se conecta con el proceso más amplio que se detecta en la modernidad a través del cual "en todo el mundo las personas sufren una 
pérdida de control sobre sus vidas"15. En lo Neopúblico la privacidad vive de manera permanente bajo la espada de Damocles que blande la Red, que, de todos modos, nunca traicionará al navegante de manera total ya que el intruso tiene que llevar a cabo una actitud activa que comienza por la iniciativa básica e inicial, la de conectarse.

Internet origina una posición igualitaria entre los usuarios. Por ello se hace difícil responder a la siguiente pregunta de interés jurídicoprocesal, que influye en la concreción de responsabilidades: ¿quiénes son particulares y quiénes personajes públicos? A ello es a lo que se refiere MUÑOZ MACHADO cuando habla de que la diferencia público-privado pierde evidencia ${ }^{16}$.

De idéntica manera, Internet relativiza el poder del Estado, al mismo tiempo que resta importancia jurídica a las fronteras. Se pierde así un elemento clave de referencia, la presencia del aparato estatal y del poder político, a la hora de articular los dos tópicos público y privado. Asimismo, se suprime la visión marcada por la idea de superioridad entre dirigentes y dirigidos, cuya traducción política es la relación gobernantes gobernados. Esa relación nace, como indica CARPIZO desde un punto de vista contractualista, "cuando un número de hombres decide unirse en sociedad, renunciando al poder de ejecutar la ley natural y, por tanto, cediéndolo a la comunidad, constituyéndose así una sociedad política o civil"17. El individuo de lo Neopúblico gravita sobre la sociedad multidireccionalmente autodeterminándose a sí mismo desde la posición heterogénea que le da la Red.

En lo Neopúblico se produce una confusión entre lo real y lo virtual, entre la realidad y la ficción. El empirismo de lo fáctico se opone a la ensoñación de lo ficticio. La experiencia sensitiva del mundo exterior frente a la recreación de la imaginación humana. Con Internet se acentúa esta paradoja del digitalismo que es el desvanecimiento de la distinción entre lo real y lo virtual. Lo virtual gana terreno y genera sensación de realidad. ¿Falsa? No, realidad virtual, una realidad distinta. "Esta nueva dimensión del ciberespacio, la digitalidad, conduce a una reinterpretación de nuestro modo de entender la técnica, puesto que en ese nuevo mundo lo real puede convertirse en falso, el original, en copia, y el ser, en identidad virtual"18. El sistema de comunicación que, en contraste con la experiencia histórica previa, genera virtualidad real es un sistema, en palabras de CASTELLS, "en el que la misma realidad (esto es, la existencia

is Castellos, Manuel: La era de la información. Vol. 2. El poder de la identidad, Alianza, Madrid, 1998, p. 92.

16 Muñoz Machiado, Santiago: La regulación de la Red, Taurus, Madrid, 2000, pp. 173-174.

17 Carpizo, Jorge: "El poder: su naturaleza, su tipología y los medios de comunicación masiva", Boletín Mexicano de Derecho Comparado, N" 95, 1999, p. 332.

is Morón Lerma, Esther: Internet y Derecho Penal: "Hacking" y otra conductas ilicitas en la Red, Aranzadi, Pamplona, 1999, p. 79. 
material/simbólica de la gente) es capturada por completo, sumergida de lleno en un escenario de imágenes virtuales, en el mundo de hacer creer, en el que las apariencias no están solo en la pantalla a través de la cual se comunica la experiencia sino que se concierten en la experiencia"19.

Ello es más complejo de lo que pueda parecer, a pesar de nuestros intentos por simplificar la aproximación analítica. La tendencia de Internet por situarse en la órbita de lo público y la cercanía de lo virtual a lo privado no es operativa en todos los casos. No es correcto entender la Red como pública y el efecto de realidad virtual que genera como privado. En efecto, las recreaciones virtuales, en principio individuales, pueden pasar al cuerpo social a través de la categoría sociológica de los imaginarios sociales, a la que ya le dedicamos algunas reflexiones en otro lugar para mostrar su eficacia en la persuasión y en la manipulación ${ }^{20}$ y sobre la que volvemos más abajo. La imagen virtual conlleva un aspecto simbólico pero también una conexión con la experiencia empírica y real del receptor. Proyección exterior en clave de condicionamientos sociales y perspectiva interior en la percepción unidas en un escalón más de lo público y lo privado.

En el espacio Neopúblico, además, se produce una relativización de la oposición entre individuo y sociedad, entre lo individual y lo colectivo. La lógica de la oferta que apuntala lo colectivo deja paso a la lógica de la demanda que emerge con la interacción de las nuevas tecnologías y al desajuste entre oferta y demanda. El individuo ya no se enfrenta a la colectividad y se protege en una urna de cristal frente a sus intromisiones. El individuo, más bien, se expande en la colectividad virtual desvaneciendo la antítesis. El modelo de comportamiento se comunitariza perfilando los vectores explicativos de una nueva ciudadanía. Es la "ciberraza" de la que habla $\mathrm{KANG}^{21}$. Internet necesita el aprendizaje de una nueva civilité que se correspondan con su funcionamiento ${ }^{22}$. Las modernas tecnologías, en un principio, favorecen la lógica individualista pero pronto esta se subsume en el nuevo espacio que surge, lo Neopúblico, donde el individuo ya no se opone a la masa. Este espacio Neopúblico no está incluido en la sociedad civil sino que se trata de algo diferente, aunque ambos espacios dan pábulo a la opinión pública, que ahora hay que entender de otro modo más complejo y heterogéneo, si bien puede permanecer como válida la caracterización de HABERMAS como "intersubjetivi-

\footnotetext{
19 Casteli.s, Manuel: La era de la información. Vol.1. La Sociedad red, Alianza, Madrid, 1997. p. 406 .

20 Fernandez Ronríguez, José Julio: "Comunicación y servicio público (una aproximación multidisciplinar)", Revista de Estudios Políticos, Madrid, No 114, 2001, pp. 189 y ss. 21 KANG, Jerry: "Cyber-race", Harvard Law Review, vol. 113, N 5, 2000, pp. 1130 y ss.

22 Vv. Aa.: Internet. Enjeux juridiques (rapport au ministre délégué à la Poste, aux Télécommunications et à l'Espace et au ministre de la Culture), La documentation Française, París, 1997. p. 12.
} 
dades de orden superior" 23 . Internet genera relaciones humanas desubicadas desde un punto de vista territorial, lo que repercute de manera directa en la posición del individuo y de la sociedad. Así las cosas, "nuevos y selectivos modelos de relaciones sociales sustituyen a formas de interacción humana limitadas territorialmente" 24 . Ello es posible gracias a que el mundo digital ofrece nuevos soportes para la sociabilidad.

De aquí se pasa a reflejar con mayor claridad la crisis de la legitimidad política tradicional, tanto de las estructuras formales del Estado de Derecho clásico como de las estructuras prestacionales del Estado Social. Los esquemas representativos que asientan semejante legitimidad pierden consistencia y fuerza con las parcelaciones que Internet implica.

La propia lógica de la corregulación presente en la Red incide en lo que estamos abordando en este momento. En efecto, la regulación estatal se conecta con la esfera de lo público y la autorregulación con la de lo privado. Postular, al hablar de corregulación, de la necesaria existencia de ambos tipos de maneras de afrontar la problemática de la regulación de la Red es un elemento más hacia la relativización de la diferencia público-privado que hacen patente lo Neopúblico como nuevo modelo analítico o, incluso, como nuevo paradigma.

La caracterización de lo Neopúblico tal vez busca asideros epistemológicos que le aporten un bagaje del que todavía carece. ¿Puede ser útil el tercer sector de la sociedad civil preconizado por algunos que no es ni público ni privado y que se opone al mercado y al gobierno?, ¿y qué decir de la tercera vía de Anthony GIDDENS? Esta búsqueda de referentes quizá no sea muy útil dados los originales rasgos de lo Neopúblico.

En fin, en lo Neopúblico se ejercen los derechos fundamentales bajo los nuevos retos y posibilidades que pone en escena la Red. Para el derecho a la intimidad surgen nuevas agresiones antes desconocidas o, si ya existían, realizadas con nuevas técnicas: elaboración de perfiles del navegante, entradas en discos duros de ordenadores, intervención de comunicaciones, acumulación de datos, hostigamiento electrónico, empleo de una dirección IP asignada a otro ordenador, suplantación de personalidad, etc. Sin embargo, y para retratar correctamente la situación, hay que hacerse eco de que el progreso técnico también aporta nuevos mecanismos de defensa de la intimidad: criptografía, claves, "cortafuegos", "sacos de arena", protocolo P3P, etc. En lo Neopúblico el derecho a la libertad de expresión e información encuentra nuevas posibilidades para su ejercicio. En efecto, en Internet se dan cita nuevas formas y vías de comunicación: el correo electrónico, los grupos de noticias, el chat (IRC) y la World Wide Web (WWW). Además, tam- 
bién se localizan y desarrollan formas de comunicación que ya existían: televisión, radio, videoconferencia o el envío de mensajes SMS. Esta nueva tesitura convierten a lo Neopúblico en el paradigma en el que circunscribir las alteraciones que se producen en la comunicación y en la vida privada.

\section{LA DINÁMICA DE LO NEOPÚBLICO}

La entrada en escena de la Red, con las implicaciones acabadas de ver en el epígrafe precedente, genera una determinada articulación de lo Neopúblico, que se concreta en una batería de consideraciones adicionales a las ya expuestas que hemos tratado de condensar en este apartado, si bien es necesario advertir al lector que ello lo hacemos desde una perspectiva funcional en el sentido de LUHMANN (y que es diferente al estructural-funcionalismo de PARSONS). Así las cosas, no enlazamos causas específicas con efectos determinados y concretos sino que, desde la idea de equivalentes funcionales del citado autor, entendemos que un criterio abstracto presenta diversas posibilidades de manifestarse.

Un fenómeno destacado es la convergencia en sentidos diversos, sobre todo en dos: entre medios, informática y telecomunicaciones; y en los propios medios. Es este segundo sentido el que nos interesa ahora ya que implica la superposición de los medios de comunicación individual, como el teléfono o el fax, y los medios de comunicación de masas, tales como la prensa, la radio y la televisión. Los primeros se orientan a la persona considerada en la individualidad que proporciona una comunicación bidireccional. Los segundos se dirigen al gran público desde la unidireccionalidad que procede de un centro emisor. Internet y el espacio Neopúblico que surge en él hacen converger los medios individuales y de masas confundiendo los aspectos individuales y públicos que implican cada uno.

Ello afecta a la propia comunicación como proceso de interacción entre emisor, mensaje y receptor. Indica WOLTON que la comunicación ha evolucionado en dos claras direcciones: la técnica y los valores de la sociedad democrática, produciéndose una combinación entre dichos valores y los resultados técnicos. Frente a esto, prosigue, en Internet ya no sabemos cuál es la lógica que mantiene a la Red, la de los valores o la de los intereses, es decir, los ideales o el comercio ${ }^{25}$. Ante este panorama arguye la necesidad de preservar esa distinción para no confundir lo normativo (en el sentido politológico de ideal) con lo funcional (o sea, el orden de la necesidad). Este diálogo "universal y multiforme, sin aparen-

25 Wolton, Dominique: (n. 5), pp. 11-12. 
tes fronteras ni más limitaciones que las que nosotros mismos nos impongamos", del que habla CEBRı́́N ${ }^{26}$, dificulta la claridad de análisis del usuario.

En lo Neopúblico la oposición entre medios de comunicación de masas y medios de comunicación individual parece romperse. La nueva tecnología acaba con la articulación lógica de esa diferencia sobre la que ha pivotado buena parte de la investigación en comunicación en las últimas décadas y separa de dos lógicas, la de la comunicación individual y la de la comunicación colectiva. Progresos como la imprenta coadyuvaron al diseño de una sociedad individualista que adquiere una complejidad abigarrada con la democracia de masas. Internet forma parte de esos hicos históricos que modifican el fenómeno de la comunicación, imprescindible en un sistema democrático y que resitúa al ciudadano en la construcción de su entorno y de su realidad. En parte, el usuario se asoma con recelo porque sabe o intuye la redefinición de la privacidad que implica lo Neopúblico.

De la confusión y convergencia en los predios de la comunicación a la confusión entre realidad y ficción. Ello aumenta los fenómenos de persuasión que venían articulándose desde diversas instancias, sobre todo desde los medios de comunicación de masas, donde se exacerba la influencia que todo proceso de comunicación conlleva. No obstante, las teorías que han valorado la influencia de los medios, que van desde el modelo hipodérmico, que la afirma muy poderosa, hasta la teoría de los efectos mínimos, que la ve como muy débil, en gran parte no nos sirven puesto que responden a una lógica unidireccional. Frente a ella, la lógica de Internet y de lo Neopúblico, como ya sabemos, es multidireccional. El éxito del proceso de persuasión, como ya tenemos indicado ${ }^{27}$, dependerá básicamente de dos factores. Uno, la propia técnica utilizada en el mismo; otro, la actitud y la aptitud del receptor. Entre ambos factores se producen una relación, no hay que considerarlos aisladamente sino en términos de compatibilidad. En efecto, un modo de persuasión puede ser adecuado para ciertos sujetos e inútil para otros, sea por las cualidades de su idiosincrasia, sea por la situación o contexto en el que se encuentran. A ello hay que añadir, en este momento, la relativización de la figura de emisor y receptor que se produce en el espacio Neopúblico, lo que introduce elemencos de ambivalencia en este juego de persuasión. La distancia y el no contacto real que tienen lugar en Internet (al igual, en este caso sí, que en los mass media) no permiten usar con la eficacia de otras situaciones recursos tales como la fuerza física. La ausencia de conexión interpersonal modula los pasos a seguir que deben ir por el camino de las

26 Cebrián, Juan Luis: La Red, Taurus, Madrid, 1998, pp. 61-62.

27 FERnÁNDEZ Rodríguez, José Julio: (n. 20), pp. 188-189. 
gratificaciones materiales o espirituales de la convicción de estar haciendo lo debido o lo mejor para los seres queridos. El receptor persuadido tienen que tener motivación suficiente para actuar. Si se logran alterar las percepciones de las condiciones de gratificación social ya se ha logrado un paso importante. Y en ello la confusión real-virtual juega su papel. El empleo de estereotipos de diversa índole, que jalonan por doquier los modernos mensajes, es un elemento a tener en cuenta en tal objetivo. De igual forma, la utilización de generalizaciones simbólicas puede, según Luhman, armonizar las propias selecciones con una realidad interpreta$\mathrm{da}^{28}$,

El empleo de imaginarios sociales es uno de los más eficaces mecanismos de manipulación y persuasión. Los imaginarios sociales, que hacen que el ser humano se represente cosas que no son, aparecen como un poderoso instrumento de dominación en manos de los diversos grupos que fácticamente ocupan el poder o de aquellos que, sin que se les pueda atribuir este calificativo, tienen la suficiente destreza y presencia en la sociedad como para utilizarlo en pos de la consecución de los objetivos que le son propios. Ello se ve subrayado cuando se desvanece la distancia entre lo público y lo privado y surge un nuevo espacio que los sustituye. Con los imaginarios sociales se posibilita el mantenimiento y prolongación en el tiempo de la dominación. Se convierten, así, en elementos a tener muy en cuenta a la hora de perfilar los significados que definen las pautas de actuación del hombre en la comunidad y en los procesos de interacción social, que la Red, virtual, matiza. La construcción del ambiente en el que se desenvuelve el ser humano se puede encontrar sometido a los referentes predefinidos que contienen estos imaginarios transmitidos por los medios, con lo que la veracidad de lo que se capta no es objetiva sino que se encuentra totalmente supeditada a la subjetivización con que opera la persona. Los mecanismos de cambio del entorno social también se ven condicionados con fuerza por este fenómeno. Poco importa que se trate de un discurso vacío o de rico contenido, los imaginarios sociales podrán operar igual. Así las cosas, llegan a organizar por completo, y desde la "clandestinidad" en la medida en que no son necesariamente percibidos, la vida diaria en sus distintos niveles y grados de complejidad. Son la imagen inconsciente que sitúa al individuo-espectador-oyente-navegante en su entorno y que le hacen inteligible los elementos discursivos que recibe cargados de contenidos ocultos y simbología. A través de su prisma esa realidad falseada aparece como realmente existente, lo virtual camina por la senda de lo real. Es creído y cré́ble. Con su uso se produce una suerte de alienación dado que aquellos que los padecen captan la realidad a través de la distorsión que de la misma producen los imaginarios sociales. Este hecho, de suyo bastante alarmante, se

28 Luhmann, Niklas: Complejidad y modernidad, Trotta, Madrid, 1998, p. 111. 
agrava aún más en la medida en que el usuario, viviendo en la "virtualidad" falsamente real, no es consciente de que está sometido a semejante proceso de restricción de su libre albedrío. De esta manera, los imaginarios sociales acaban por incorporarse al subconsciente de las personas para las cuales han sido creados. Al mismo tiempo que permiten ejercer dominio también posibilitan una cierta paz social porque la gente va a creer aquello que transmite el imaginario a través del medio sin preocuparse ni de un análisis más profundo ni de una hipotética verificación acerca de la certeza de la información transmitida.

Evidentemente, los imaginarios sociales son de muy diversos tipos y su proceso de formación varía de manera sustancial de unos supuestos a otros. En el ámbito de la política su paulatina configuración histórica a través de los medios de comunicación es innegable, pero ahora adquiere una nueva reordenación con la Red y lo Neopúblico. A veces, este proceso respondió a estrategias predefinidas; en otras ocasiones, se originó por coincidencias no planificadas. Sea como fuere, una vez que determinado imaginario político se ha instaurado en el seno de una sociedad, su eliminación y/o sustitución resulta arriesgada para los entes que la intenten llevar a cabo, puesto que pueden ser tachados de actuar contra el sistema y eliminados del mismo. No obstante, sí es posible este cambio en los imaginarios políticos, que se ve a veces favorecido por la simple fuerza de las cosas y el devenir histórico. Es curioso ver cómo la heterogeneidad de la modernidad ha provocado una homogeneización de lo que se considera esencial para sustentar el sistema político utilizando los mass-media, que en este sentido pretenden encontrar una correa de transmisión en Internet.

La dinámica de lo Neopúblico genera consecuencias psicológicas relativas a la sensación de apertura y de liberación antropológica. De ahí se pasa a la sensación de libertad en este nuevo espacio que supera la vieja dialéctica público-privado. WOLTON es claro en este sentido al indicar que "las dimensiones psicológicas son esenciales en la atracción por las nuevas tecnologías, ya que estas reúnen el profundo movimiento de individualización de nuestra sociedad". "Cada uno -prosigue- puede actuar sin intermediario cuando quiera, sin filtros ni jerarquías y, lo más importante, en tiempo real", de lo que se deriva "un sentimiento de libertad absoluta, incluso poder", ejemplificado en la expresión "navegar por la Red" 29 . Esta responde a esa necesidad de actuar del ser humano creando con su interactividad un mundo de relaciones en el ciberespacio que difieren de las que se tienen en el mundo físico. Una necesidad de actuar que se mueve por parcelas creativas para dar rienda suelta a la imaginación que preside lo Neopúblico, donde las barreras sociales y culturales 
son inexistentes y el espíritu de libertad resulta más acentuado. Las actividades del usuario no son nihilistas sino que obedecen a una nueva forma de compromiso solidario que habita ese nuevo espacio que surge tras el desvanecimiento de la oposición público-privado. Siendo así las cosas, la utopía de Internet es seductora. Se ha convertido "en el soporte de sueños eternos para una nueva solidaridad, aunque sea un poco triste constatar la diferencia entre la calidad de estas utopías y los comportamientos terriblemente eficaces de los proveedores del templo, de esas industrias tan alejadas de este ideal de solidaridad" ${ }^{30}$. Esta dialéctica, entre soñadores utópicos y la lógica económica, está por resolver.

La soledad que puede generar como consecuencia la Red es una soledad interactiva $y$, por lo tanto, diferente a otras. "La interactividad, propia de la comunicación en línea, permite un diálogo entre el difusor y el receptor, que es lo que tiende a convertir todos los medios de comunicación convencionales, explotados electrónicamente, en un mismo medio, con las posibilidades de todos ellos" 31 . Esta interactividad muda el comportamiento de la persona, los "hábitos, estilos de vida, actitudes, uso del tiempo de ocio, espacio de trabajo" 32 , con lo que se está pregonando un cambio social. La eliminación de la carga temporal que exige una comunicación en el mundo analógico y su sustitución por un concepto nuevo de tiempo en la Red, liso, es otro reto antropológico en lo Neopúblico que se compensa con las relaciones emocionales que, sin duda, contextualizan en todo momento al navegante y ayudan a la precomprensión. Este nuevo tiempo es un tiempo comprimido que busca la quimera de la actuación en tiempo real. Cada uno fabricará su libertad y su tiempo Neopúblico, quizá movido por una especie de ideal de transparencia inalcanzable. El tiempo de lo Neopúblico lleva a articular dimensiones nuevas para la comprensión. Las diferencias entre emisor, receptor y mensaje se sostienen desde la lógica analítica de lo público o de lo privado, pero no tanto con las relativizaciones que impone Internet, aunque no se pierde el componente cultural de la comunicación porque la técnica no acaba con el ser humano y su emotividad, ni con la categoría de ciudadano opuesta a la de consumidor pese a las ambigüedades que se generan. Semejante tiempo sirve también para la permanencia que requiere la construcción cultural, acumulada capa tras capa y rehecha por la dinámica nada perenne de la Sociedad de la Información, que impone un modelo cultural (o multicultural) que va más allá de la superada

\footnotetext{
30 Ibidem, p. 99.

31 Cousido González, María Pilar: Derecho de la comunicación en Internet, Colex, Madrid, 2001, pp. 216-217.

32 Diezhandino Nieto, María Pilar: "El periodismo de servicio en los tiempos de Internet", en LÓPEZ, Xosé (dir.), Tendencias en el periodismo, EGAP-Montecorvo, Madrid, 2001, p. 230 .
} 
oposición entre cultura popular y cultura de élites. El tiempo de lo Neopúblico genera un universo volátil y fugaz que se extingue y reaparece continuamente. Los nuevos medios que habitan en esta realidad (o irrealidad) temporal rompen las barreras del tiempo "al ser el tiempo de las redes continuo e instantáneo, no solo desde la perspectiva del difusor, sino también desde la perspectiva del público", que puede "ejercer las facultades de investigación y de difusión y profesionalizarse e, incluso, organizarse, en ese ejercicio, de una forma que los medios convencionales no lo permitirían" 33 .

Este nuevo tiempo se ubica también en un nuevo espacio, el virtual o digital, que, como indican Terceiro y Matías, "más allá de quedar en meros conceptos", el espacio y tiempo digitales "tienen presencia real en las diversas manifestaciones de la vida social, por lo que cabe pensar no solo en su consolidación, sino en su extensión" 34 . Señala NEGROPONTE que la vida digital trae consigo "una dependencia cada vez menor con respecto a estar en un lugar específico y en un momento específico, e incluso el cambio de lugar empezará a ser posible" 35 . De esta forma, la ubicación física se vuelve un tanto volátil o, como apunta MORÓN LERMA, "la categoría de lugar se dispersa y se vuelve evanescente, fantasmagórica, plural, compartible, híbrida, ubicua". A lo que añade que el "sujeto puede materializar, incondicionado por el tiempo y el lugar, todas las formas de identidad antes solo soñadas y sublimadas"36. El nuevo espacio desempeña sus roles en arquitecturas diversas ya que "el ciberespacio no es un lugar, sino muchos lugares, y las características de cada uno de ellos no son idénticas" 37 . El espacio real se imbrica en el virtual en correlaciones que a veces causan sorpresa. La vida en lo Neopúblico es también la vida en el espacio real. El mundo físico en el que vivimos y sentimos se prolonga y extiende en las parcelas de lo Neopúblico desapareciendo poco a poco y haciendo emerger este nuevo espacio-tiempo, que también reconocen los sentidos de la persona. PAUL, tras recoger la idea de ROSNAY de "ecosistema informacional", habla de "los sistemas de comunicación que se multiplican" y "abren la puerta a un nuevo espaciotiempo económico, sociológico y cultural"38. Este espacio-tiempo Neopúblico, que difumina la distinción público y privado, abre horizontes y genera pautas de ubicación, es decir, cultura, la cultura de lo Neopúblico. Esta cultura creemos que es una hibridación de lo que se considera como

\footnotetext{
33 CuUsino GonzÁlez, María Pilar: (n, 31), p. 216.

34 Terceiro, José B. y Matías, Gustavo: El digitalismo. El nuevo horizonte sociocultural, Taurus, Madrid, 2001, p. 46.

35 Negroponte, N.: El mundo digital, Ediciones B, Barcelona, 1999, p. 198.

36 MORÓN LERMA, Esther: (n. 18), p. 92.

37 Lessig, Lawrence: El código y otras leyes del ciberespacio, Taurus, Madrid, 2001, p. 125.

38 PAUl, Christian: Du droit et des libertés sur Internet, La Documentación Française, París, 2001 , p. 31.
} 
la cultura de Interner, que en opinión de CASTELLS se caracteriza "por tener una estructura en cuatro estratos superpuestos: la cultura tecnomeritocrática, la cultura backer, la cultura comunitaria virtual y la cultura emprendedora" 39 .

La cultura de lo Neopúblico construye una nueva sociedad que transforma las relaciones humanas, también desde un punto de vista económico ya que la base material y tangible deja paso a los elementos intangibles. La información es vital en la esfera sociocultural de lo Neopúblico, que se alimenta del acceso y de la interconexión. Esta información se apoya en las conquistas técnicas para mejorar cuantitativa y cualitativamente. "La promesa de la era de la información -sentencia CASTELLS- es la liberación de una capacidad productiva sin precedentes por el poder de la mente" 40 . Técnica e información en un nuevo paradigma del que habla MATTELART: "el paradigma tecnoinformacional se ha convertido en el pivote de un proyecto geopolítico cuya función es la de garantizar la reordenación geoeconómica del planeta en torno a los valores de la democracia de mercado y en un mundo unipolar" 41 . No obstante, este aparente mundo unipolar no lo es tal ya que las riquezas que en términos de pluralismo y participación aporta la Sociedad de la Información y su estandarte, Internet, permiten no solo mantener sino también incrementar las visiones geopolíticas del mundo.

La persona se desarrolla y socializa en este novedoso contexto en un proceso de retroalimentación galvanizado por la tecnología. Esto demuestra la permeabilidad de la cultura y de sus fronteras. Esta cultura de lo Neopúblico, acelerada por diversas cuestiones y frenada por otras, tiene sus propios símbolos que facilitan la comprensión de la comunicación y el desarrollo del conocimiento (se ha dicho que la computadora implica un sistema simbólico desde el principio: los impulsos eléctricos son tratados como significantes con significados diferentes-ceros y unos- que componen simples operaciones matemáticas que, a su vez, representan palabras o imágenes, hojas de cálculo o mensajes de correo electrónico ${ }^{42}$ ). Siendo así las cosas, surgen nuevas relaciones sociales, pero no producto exclusivo de la tecnología sino consecuencia de todo el conjunto de fenómenos que se experimentan. Aparece un "nuevo tipo de persona, el sujeto digital, que (...) conforma un nuevo tipo de socie-

\footnotetext{
39 Castells, Manuel: (n. 24), p. 51.

40) Castells, Manuel (1999), La era de la información. Vol. 3. Fin de Milenio, Alianza, $2^{*}$ ed., Madrid, 1999, p. 412.

41 Mattelart, Armand: La mundialización de la comtnicación, Barcelona, Paidós, Barcelona, 2002 , p. 136.

42 Terceiro, José B. y Matias, Gustavo: (n. 34), p. 105.
} 
dad" 43 . El ser humano que viene será hijo de este horizonte y entenderá que parte de su privacidad corre el riesgo de no ser solo suya y que sectores públicos son adueñados por elementos reprivatizadores en un conjunto de vectores que confluyen en el nuevo espacio-tiempo cultural de lo Neopúblico. El ejercicio de derechos fundamentales debe afrontar todo este desafío.

Pese a lo dicho, semeja oportuno cerrar estas reflexiones con una advertencia que permita entender las afirmaciones realizadas en su justa medida. Los cambios a que se ve sometida la persona en la vorágine del espacio Neopúblico que nace en Internet no generan por sí mismo mutaciones culturales, aunque sean una de las variables a tener en cuenta en ese sentido. Las pautas culturales y de socialización provienen de unos condicionantes internos y externos de distinta naturaleza y con diferente capacidad de influencia. Por importante que sean las alteraciones originadas por Internet, por sí solas no son gran cosa en el marco de referencia de la persona que le permite situarse en el mundo. Aceptar lo contrario es claudicar ante un determinismo técnico deshumanizante que desconoce la grandeza de las relaciones humanas.

\section{BiBLIOGRAFÍA CONSULTADA}

- Basterra, Marcela I.: "Libertad de prensa versus derecho a la intimidad", en VV. AA., Poder político y libertad de expresión, AbeledoPerrot, Buenos Aires, 2001.

- CARPIZO, Jorge: "El poder: su naturaleza, su tipología y los medios de comunicación masiva", Boletín Mexicano de Derecho Comparado, $\mathrm{N}^{\circ}$ 95, 1999.

- Castells, Manuel (1999), La era de la información. Vol. 3. Fin de Milenio, Alianza, $2^{a}$ ed., Madrid, 1999.

- CASTElls, Manuel: La era de la información. Vol. 2. El poder de la identidad, Alianza, Madrid, 1998.

- CASTells, Manuel: La era de la información. Vol.1. La Sociedad red, Alianza, Madrid, 1997.

- Castells, Manuel: La galaxia Internet, Areté, Madrid, 2001.

- Cebrián, Juan Luis: La Red, Taurus, Madrid, 1998.

- Cousido González, María Pilar: Derecho de la comunicación en Internet, Colex, Madrid, 2001.

- DADER, José Luis: Periodismo de precisión: la vía socioinformática de descubrir noticias, Síntesis, Madrid, 1997.

- De CABo DE LA VEGA, A.: Lo público como supuesto constitucional, Instituto de Investigaciones Jurídicas, Universidad Nacional Autónoma de México, México D. F.

43 MORÓN LERMA, Esther: (n. 18), p. 79. 
- Diezhandino Nieto, María Pilar: "El periodismo de servicio en los tiempos de Internet", en LÓPEZ, Xosé (dir.), Tendencias en el periodismo, EGAP-Montecorvo, Madrid, 2001.

- Echeverría EZPONDA, Javier: "Democracia y sociedad de la información", Isegoria, $\mathrm{N}^{\circ} 22,2000$.

- Fernández Esteban, María Luisa: Nuevas tecnologías, Internet y derechos fundamentales, McGraw-Hill, Madrid, 1998.

- Fernández Rodríguez, José Julio: "Comunicación y servicio público (una aproximación multidisciplinar)", Revista de Estudios Politicos, Madrid, N 114, 2001.

- Fernandez Rodríguez, Julio José: Lo público y lo privado en Internet. Intimidad y libertad de expresión en la Red, Instituto de Investigaciones Jurídicas, Universidad Nacional Autónoma de México, México D. F., 2004.

- Freund, Jürgen: L'essence du politique, Sirey, $3^{a}$ ed., París, 1981.

- Habermas, Jürgen: El discurso filosófico de la modernidad, Taurus, Madrid, 1989.

- KANG, Jerry: "Cyber-race", Harvard Law Review, vol. 113, No 5, 2000.

- Lessig, Lawrence: El código y otras leyes del ciberespacio, Taurus, Madrid, 2001.

- Luhmann, Niklas: Complejidad y modernidad, Trotta, Madrid, 1998.

- Mattelart, Armand: La mundialización de la comunicación, Barcelona, Paidós, Barcelona, 2002.

- MAYOR, Pablo y DE AReILZA, José M.: Internet, una profecía, Ariel, Barcelona, 2002.

- MORÓN Lerma, Esther: Internet y Derecho Penal: "Hacking" y otra conductas ilícitas en la Red, Aranzadi, Pamplona, 1999.

- MuÑoz Machado, Santiago: La regulación de la Red, Taurus, Madrid, 2000.

- Negroponte, N.: El mundo digital, Ediciones B, Barcelona, 1999.

- PAul, Christian : Du droit et des libertés sur Internet, La Documentación Française, París, 2001.

- Puy Muñoz, Francisco: Tópica Jurídica, Paredes, Santiago de Compostela, 1984.

- Ruiz Miguel, Carlos: Servicios de inteligencia y seguridad en el Estado Constitucional, Tecnos, Madrid, 2002.

- Terceiro, José B. y Matías, Gustavo: El digitalismo. El nuevo horizonte sociocultural, Taurus, Madrid, 2001.

- Wolton, Dominique: Internet ¿y después?, Gedisa, Barcelona, 2000.

- Vv. AA.: Internet. Enjeux juridiques (rapport au ministre délégué à la Poste, aux Télécommunications et à l'Espace et au ministre de la Culture), La documentation Française, París, 1997. 